EGU2020-8286

https://doi.org/10.5194/egusphere-egu2020-8286

EGU General Assembly 2020

(c) Author(s) 2020. This work is distributed under

the Creative Commons Attribution 4.0 License.

\title{
Spatial distribution of (137)Cs in reference soil sites of South America to reconstruct soil erosion in intensive agricultural landscapes during the Anthropocene
}

Pierre-Alexis Chaboche, Olivier Evrard, and Irène Lefèvre

Laboratoire des Sciences du Climat et de I'Environnement (LSCE/IPSL), Université Paris-Saclay, UMR 8212 (CEA-CNRS-UVSQ), Gif-sur-Yvette, France

Land degradation and fine sediment supply induced by soil erosion processes are exacerbated in intensively cultivated catchments of South America, leading to deleterious consequences for ecosystems and to the disturbance of global biogeochemical cycles. In order to evaluate the sustainability of agricultural practices, a fundamental prerequisite is to quantify soil erosion rates and compare them with the tolerable soil losses. Although its use has been debated in the literature, the fallout radionuclide (137Cs) is one of the few techniques available to reconstruct soil redistribution rates during the Great Acceleration period. Accordingly, it is increasingly used to quantify soil redistribution rates in catchments across the world. Assessment of erosion and deposition rates is commonly based on the comparison of (137Cs) inventories in undisturbed soil profiles (i.e. where neither erosion nor deposition has occurred) and those measured at locations affected by soil redistribution in the landscape. However, in intensive agricultural landscapes, appropriate reference sites can be difficult to find. The objective of this study is to determine and map the initial (137Cs) fallout at the scale of South America, based on measurements made on reference soil sites and spatialized co-variables. This new map will be useful for the scientific community and public authorities to evaluate the sustainability of farming practices, especially in the eastern part of South America where intensive agricultural practices dominate. Furthermore, the methodology presented here could be applied to other regions located in the Southern Hemisphere in order to avoid the systematic sampling of reference sites for conducting soil erosion studies using the (137Cs) technique. 